\title{
A Clinical Audit on Diabetes Care in Patients with Type 2 Diabetes in Al- Ain, United Arab Emirates
}

\author{
Abdulla Shehab $^{* 1,3}$, Asim Elnour $^{2,4}$ and Abdishakur Abdulle ${ }^{1}$ \\ ${ }^{1}$ Department of Internal Medicine, ${ }^{2}$ Department of Pharmacology; College of Medicine, United Arab Emirates Univer- \\ sity (UAEU) \\ ${ }^{3}$ Department of Cardiology, ${ }^{4}$ Department of Pharmacy; Al-Ain Hospital in affiliation with VAMED and Medical Univer- \\ sity of Vienna, Abu Dhabi Health Services Company (SEHA); Al-Ain, UAE
}

\begin{abstract}
Objectives: To implement a prospective interventional clinical audit to evaluate the current clinical practice and the effect of standard interventions on the management of type 2 diabetes (T2DM).

Methods: 254 patients with T2DM where recruited in a specialized diabetes care center in Al-Ain, UAE. The diabetes care components were audited before (baseline) and after (3 and 6 months) implementation of Institute of Clinical System Improvement (ICSI) guidelines. Data was compared against international guidelines to achieve target goals of normoglycemia, blood pressure (BP), and low density lipoprotein-cholesterol (LDL-C). We measured changes in mean scores of patient satisfaction level regarding diabetes care at similar intervals, by validated Patient Satisfaction Questionnaire (PSQ18).

Results: We observed a significant reduction in fasting blood glucose (FBG; mean \pm SD; $9.3 \pm 0.03$ vs $7.4 \pm 0.3 \mathrm{mmol} / \mathrm{l}$; $P=0.03)$, and $\mathrm{HbA}_{1 \mathrm{c}}(8.7 \pm 0.02$ vs $8.1 \pm 0.02 \% ; P=0.04)$ levels after 6 months compared with baseline. Patients who achieved target FBG and $\mathrm{HbA}_{1 \mathrm{c}}$ levels improved significantly (45.7 vs $\left.81.1 \% ; P=0.03\right)$, and (40.1 vs 73.6\%; $\left.P=0.04\right)$, respectively. The LDL-C levels improved, though this was not statistically significant. Patients achieving target of BP control improved significantly (SBP $142 \pm 7.6$ and DBP $95 \pm 6.2$ vs SBP $136 \pm 8.2$ and DBP $87 \pm 5.8 \mathrm{mmHg} ; P=0.05$ ).

Conclusions: The results of this interventional audit were generally positive and emphasized the feasibility of improving the current clinical practice. Our individualized approach has helped us to achieve a better target in glycemic and BP control as well as patient satisfaction. Further research is needed to understand the long-term impact of our structured approach to improve the quality of T2DM care in the UAE.
\end{abstract}

Keywords: Al Ain, Audit, Care, Clinical, Diabetes, UAE.

\section{INTRODUCTION}

The global burden of type 2 diabetes (T2DM) is increasing, particularly, in economically developing countries [1]. Epidemiological studies suggest that, without effective prevention and control programs, T2DM is likely to continue to increase globally $[2,3]$. The United Arab Emirates (UAE), a country under developmental transition, has one of the highest prevalence of T2DM worldwide [1,4], with significant T2DM-relatedcomplications [5], and cost of treatment [6]. Despite substantial efforts at the national level, and high standard healthcare facilities, no evidence exists to justify changes in the current practice for prevention and treatment of T2DM in the UAE.

Clinical audit presents a practical approach to systematically evaluate the quality of patient care, and identify treat

*Address correspondence to this author at the cardiovascular medicine Vice President Emirates Cardiac Society College of Medicine, UAE University, P.O.Box 17666, Al Ain, UAE; Tel: 00971506161028;

Fax:+97137672995; Email: a.shehab@uaeu.ac.ae ment gaps between current practice and target goals [7-9]. Of note is the level of glycemia, blood pressure (BP), and lipid profile, which plays a significant role in reducing macro- and micro-vascular complications [10], and improve quality of life [11], Moreover, patient satisfaction may enhance treatment compliance [12].

Several clinical audits in the UAE reported modest improvements in some key indicators. Nevertheless, these studies either used a small sample size [13], or produced inconclusive results $[14,15]$.

To identify treatment gaps, we carried out interventional clinical audit for T2DM care pre- and post-implementation of T2DM care international guidelines from the Institute for Clinical Systems Improvement (ICSI) [16].

\section{METHODS}

The Al-Ain Medical District Human Research Ethics Committee approved the protocols of the study. Enrolled subjects signed a consent letter to participate in the study. 


\section{Subjects}

A total of 254 enrolled subjects with T2DM were randomly selected and followed up for 6 months (February July, 2009) during routine visits to specialized medical clinics in Al-Ain hospital, Al-Ain, UAE.

\section{Data Collection/ Current Practice}

At baseline, we reviewed patient charts, before and after implementation of ICSI standards [16]. Patient data was collected from patient's diabetes flow-chart, and process measures data including $\mathrm{HbA}_{1 \mathrm{c}}$, fasting blood glucose (FBG), BP, and lipid profile. In addition, other indicators were reviewed and reported; drug regimen, and routine evidence of T2DM complications. ICSI standards were used to verify current patients' T2DM status and plan for achieving the target.

\section{Clinical Measurements}

We measured body weight, height, $\mathrm{BP}, \mathrm{HbA}_{1 \mathrm{c}}, \mathrm{FBG}$, serum lipids, creatinine, and urea nitrogen, at scheduled clinic visits ( 3 intervals) during the study period. Body mass index (BMI) was calculated as weight $(\mathrm{kg}) /$ height $(\mathrm{m})^{2}$. All laboratory parameters were measured as part of the normal clinical investigations and by standard methods.

\section{Intervention Program}

Following the collection of the baseline data, individualized and comprehensive performance measures of diabetes care, were deployed with anticipated goals of increased percentage of patients who achieved established control levels. In all aspects of diabetes care and counseling (lifestyle intervention, self- management through education, and selfmonitoring of blood glucose), we followed national and international guidelines [16, 17].

A focused cardiovascular risk reduction program, individualized $\mathrm{HbA}_{1 \mathrm{c}}$ target $(<6.5 \%)$, patients involvement in the decision making process, recognition of hypoglycemia and hyperglycemia episodes were emphasized. Accordingly, insulin dose and oral antidiabetic therapy were adjusted and administered. Targeted BP control was $[\leq 130 / 80 \mathrm{mmHg}$ for patients with diabetes and $125 / 75 \mathrm{mmHg}$ for patients with proteinuria $(>1 \mathrm{~g} /$ day) $]$. To accomplish BP target, in additional to tailored life style modification we also frequently tailored $\geq 2$ antihypertensive medications with frequent BP monitoring as per guidelines. To achieve a target LDL-C control $(\leq 2.5 \mathrm{mmol} / \mathrm{l})$, statins were tailored to patient clinical status, symptoms and tolerability. Other measures were close evaluation patients for clinical complications, i.e., eye examination, foot risk assessments, examination for neuropathy, and screening for proteinuria.

\section{Patient Satisfaction}

To identify patient satisfaction regarding diabetes care, we used 2 validated $t$ questionnaires pertaining general [patient satisfaction questionnaire (PSQ-18)], and specific [diabetes satisfaction questionnaire (DSQ)], and measured the outcome at baseline, 3 months and 6 months.

\section{Patient Satisfaction Questionnaire [PSQ-18]}

A validated PSQ-18 tool was used for diabetes clinical audit inquiring of patients' satisfactions with medical care (offered care) and agreement whether new treatment modalities met a satisfactory standard of medical care. Again, survey data, with regards to patients' satisfaction, was collected at baseline and after implementation of standard criteria (ICSI) which was preceded with a campaign, i.e., successive workshops and discussions to raise awareness about agreed standards of care. The PSQ-18 questionnaire was utilized with a permission from RAND Corporation, Santa Monica, California (USA) and basic guidelines for translating PSQ18 were specifically followed $[18,19]$.The PSQ-18 yields separate scores for each of 7 different subscales: general satisfaction (items 3 and 17); technical quality (items 2, 4, 6, and 14); interpersonal manner (items 10 and 11); communication (items 1 and 13); financial aspects (items 5 and 7); time spent with doctor (items 12 and 15); accessibility and convenience (items 8, 9, 16, and 18). Some PSQ-18 items are worded implying agreement reflects satisfaction with medical care, whereas other items are worded so that agreement reflects dissatisfaction with medical care. All items were scored; high scores reflect satisfaction with medical care. After item scoring, items within same subscale were averaged together to create 7 subscale scores. Scale scores represent average for all items in scale that were answered.

\section{Diabetes Satisfaction Questionnaire (DSQ)}

We developed a modified Diabetes satisfaction questionnaire (DSQ) from validated international tools $[20,21]$. The DSQ was pre-tested for internal consistency(Cronbach's alpha, $>0.7)$, validated by a panel of experts and was piloted with a random conveniencesample of 48patients with T2DM. The pilot phase was not included in the study sample.

The DSQ contained 7 questions aimed mainly at identifying specific domains of diabetes care including adherence to medications, eye/foot examinations, advice on diet, exercise, and self-monitoring of blood glucose. The questionnaire specifically tested participant's satisfaction with delivered diabetes care, performance of healthcare providers, and reasons, if any, for dissatisfaction.

\section{Statistical Analysis}

Data were analyzed using SPSS version 18 (SPSS Inc., Chicago, IL). Categorical variables were tested using Chisquared $\left(\chi^{2}\right)$ analyses. Student's paired and unpaired t-tests, one-way ANOVA and a post hoc multiple comparison tests were used to compare variables at different intervals. Difference in outcome was measured between baseline, audit and re-audit data (for both data sets) and a $\mathrm{p}<0.05$ (twotailed)was significant.

\section{RESULTS}

The mean age \pm SD of all participants $(n=254)$ was $(49$ \pm 2.1 years; $47 \%$ females). The majority of subjects were either overweight $(53 \%)$, or obese $(29 \%)$ based on standard BMI values. Approximately $75 \%$ of subjects reported a 
common family history of T2DM, but without history of smoking (Table 1).

Table 2 shows the comparison data of target parameters of diabetes care at baseline, 3 months, and 6 months. There was a significant reduction in FBG level $(9.3 \pm 0.03$ vs $7.4 \pm$ $0.3 \mathrm{mmol} / 1 ; P=0.03)$, and the percentage of subjects who reached target FBG levels increased from $45.7 \%$ at baseline to $81.1 \%$ after 6 months.

Similarly, we observed a significant reduction in $\mathrm{HbA}_{1 \mathrm{c}}$ levels $(8.7 \pm 0.02$ vs $8.1 \pm 0.02 \% ; p=0.04)$. The percentage of patients who reached target $\mathrm{HbA}_{1 \mathrm{c}}$ levels improved from $40.1 \%$ at baseline to $73.6 \%$ after 6 months. Both LDL-C levels $(2.6 \pm 0.03$ vs $2.5 \pm 0.2 \mathrm{mmol} / \mathrm{l})$ and the respective percentage of subjects (54.3 vs $62.2 \%$ ) who reached target levels, improved, although this difference was not significant, after 6 months compared with baseline.

At baseline BP levels were [SBP $142 \pm 7.6$ and DBP $95 \pm 6.2 \mathrm{mmHg}$, and were improved to [SBP $136 \pm 8.2$ and DBP $87 \pm 5.8 \mathrm{mmHg}]$ after 6 months, but the difference was not significant. However, the percentage of subjects with improved BP below target levels was statistically significant (33.9 vs $69.2 \% ; P=0.041$ ) from baseline and after 6 months, respectively.

Data revealed significant difference $(P=0.035)$ in macrovascular complications between baseline $(10.2 \%)$ and after 6 months (7.9\%). Micro-vascular complications were slightly lower after 6 months $(14.2 \%)$ than baseline $(15.7 \%)$, although this difference was not significant (Table 2).

\section{Results of Patient Satisfaction Questionnaire (PSQ-18)}

Table 3a shows the results of the general PSQ-18. The responses to PSQ-18 at baseline varied considerably across continuum of the general medical care. Patients responded negatively to all questions that addressed their satisfaction with the 'medical care system' and with 'provided healthcare' with few exceptions. Interestingly, patient satisfaction level increased considerably, post-baseline, as subjects responded more positively in most of statements with significant difference in responses between baseline and postbaseline assessment $(P<0.05)$.

Table $3 \mathbf{b}$ shows the scores of both the positively and negatively worded domains and sub domains of the PSQ18. In all of the 7 domains, there was a significant improvement in scores of general satisfaction, technical quality, interpersonal manner, communication, time spent with doctor, accessibility and convenience, but not financial aspects.

\section{Results of Diabetes Satisfaction Questionnaire (DSQ)}

Respondents exhibited positive improvement in all seven domains of DSQ with an upward pattern of significant differences between baseline and post-baseline in all aspects of diabetes care $[P<0.05]$. At baseline assessments, more than half of the subjects have not been offered eye and foot examinations. Whilst, over two third of subjects were not counseled about their adherence to prescribed regimen [ $n=$ $90,(70.9 \%)]$. Slightly over half have not been offered advice on their diet. Furthermore, majority of subjects have not been offered advice on exercises activities. Also, more than half were not satisfied with healthcare providers $(57.5 \%$,
Table 1. Demographic and Clinical Characteristics of Patients with Type 2 Diabetes, $n=254$

\begin{tabular}{|c|c|}
\hline Parameter & Frequency (\%) \\
\hline \multicolumn{2}{|l|}{ Age groups } \\
\hline Age (mean \pm SD) & $49(2.1)$ \\
\hline$<50$ years & $126(49.6)$ \\
\hline$\geq 50$ years & $128 *(50.4)$ \\
\hline \multicolumn{2}{|l|}{ Gender } \\
\hline Male & $134 *(52.8)$ \\
\hline Female & $120 \quad(47.2)$ \\
\hline \multicolumn{2}{|l|}{ BMI $\left(\mathrm{Kg} / \mathrm{m}^{2}\right)$} \\
\hline$\leq 25$ & $46 \quad(18.1)$ \\
\hline$>25$ to $<30$ & $134 *(52.8)$ \\
\hline$>30$ & $74 \quad(29.1)$ \\
\hline \multicolumn{2}{|l|}{ Marital status } \\
\hline Married & $190 *(74.8)$ \\
\hline Unmarried & $64 \quad(25.2)$ \\
\hline \multicolumn{2}{|l|}{ Smoking } \\
\hline Current smoker & $33 \quad(13.0)$ \\
\hline Ex-smoker & $10 \quad(3.9)$ \\
\hline Never smoked & $187 *(73.6)$ \\
\hline Not documented & $24(9.5)$ \\
\hline \multicolumn{2}{|l|}{ Family history of diabetes } \\
\hline Yes & $172 *(67.7)$ \\
\hline No & $82 \quad(32.3)$ \\
\hline \multicolumn{2}{|c|}{$\begin{array}{l}\text { Date of diabetes diagnosis (years) Mean }( \pm \mathrm{SD}) \text { duration of diabetes in } \\
\text { years }(8 \pm 3.2)\end{array}$} \\
\hline$<1$ & $42 \quad(16.5)$ \\
\hline$>1$ and $<5$ & $58 \quad(22.8)$ \\
\hline$>5$ and $<10$ & $60 \quad(23.6)$ \\
\hline$>10$ & $94 *(37.1)$ \\
\hline \multicolumn{2}{|l|}{ Medical history } \\
\hline History of hypertension & $67 \quad(26.4)$ \\
\hline History of dyslipidaemia & $93 *(36.6)$ \\
\hline $\mathrm{H} / \mathrm{O}$ other co morbid conditions & $83 \quad(37.0)$ \\
\hline \multicolumn{2}{|l|}{ Other co morbidities } \\
\hline Presence of co morbid conditions & $147 *(57.9)$ \\
\hline None & $107 \quad(42.1)$ \\
\hline \multicolumn{2}{|l|}{ Treatment modalities } \\
\hline Lifestyle modification alone & $12(4.7)$ \\
\hline Oral hypoglycemic agents (OHA) & $159 *(62.6)$ \\
\hline OHA and Insulin & $62(24.4)$ \\
\hline Insulin only & $21 \quad(8.3)$ \\
\hline
\end{tabular}

Key: *The highest percentage achieved in sub rows. 
Table 2. Comparison of Target Parameters (Fasting) and Clinical Outcomes of Diabetes Care at Baseline, Three Months, and Six Months, $n=254$

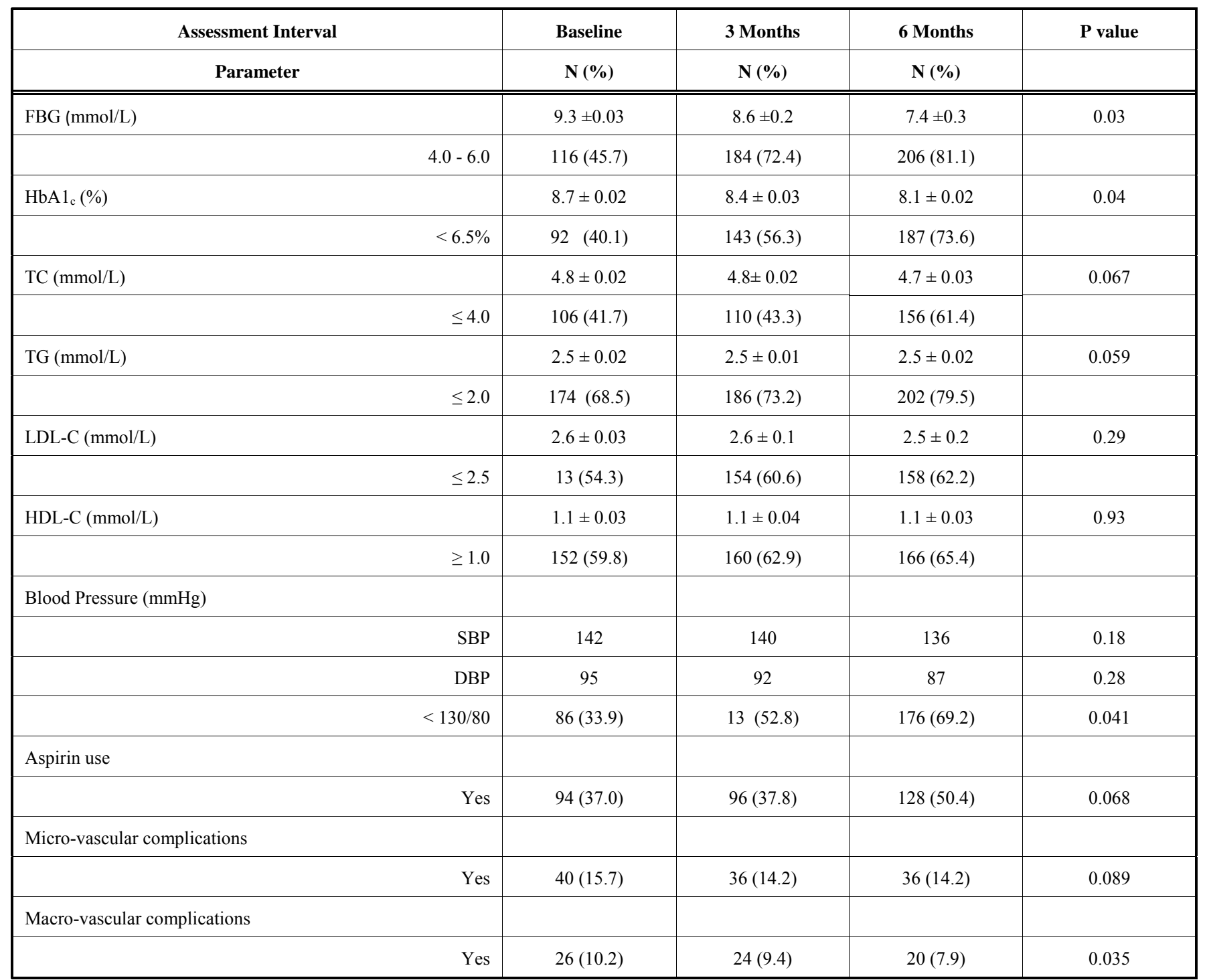

Note: Target blood pressure: $<130 / 80 \mathrm{~mm} \mathrm{Hg}$ for people with diabetes and $\leq 125 / 75 \mathrm{~mm} \mathrm{Hg}$ for people with proteinuria (>1g/day), Microvascular complications: retinopathy, nephropathy, neuropathy; Macrovascular complications: Cerebrovascular Disease, e.g. stroke/Transient Ischaemic Attacks (TIAs), foot ulceration or amputation, Ischaemic Heart Disease (IHD), e.g. Angina/Myocardial Infarction, Peripheral Vascular Disease, e.g. Claudication/Gangrené. FBG: Fasting Blood Glucose, HbA1c: Glycosylated hemoglobin, TC: Total Cholesterol, TG: Triglycerides, LDL-C: LDL- Cholesterol, HDL-C: HDL-Cholesterol.

$\mathrm{n}=146)$ vs $(42.5 \%, \mathrm{n}=108)$ neither with delivered diabetes care $(52.8 \%, \mathrm{n}=134)$ vs $(47.2 \%, \mathrm{n}=120)$. After 3 months, DSQ positive responses increased. For example, nearly two thirds of patients were satisfied with healthcare providers $(63.8 \%, \mathrm{n}=162)$ vs $(36.2 \%, \mathrm{n}=92)$ as well as with offered diabetes care $(67.7 \%, \mathrm{n}=172)$ vs $(32.3 \%, \mathrm{n}=82)$. More improvements in majority of DSQ were attained during second assessment with more positive responses. This was clearly exemplified by satisfaction with offered diabetes care $(87.4 \%, \mathrm{n}=222)$ vs $(12.6 \%, \mathrm{n}=32)$.

\section{DISCUSSION}

This interventional audit study highlights the current clinical practice of T2DM care, and provides a foreseeable opportunity for improvement in the delivered care in outpatient clinics. The implementation of ICSI standards has had a significant and positive effect on both the delivery of diabetes care, and clinical outcome.

A significant reduction was achieved in $\mathrm{FBG}$ and $\mathrm{HbA}_{1 \mathrm{c}}$ levels with a considerable increase in the percentage of subjects achieving target $(81 \%$ and $73.6 \%)$, respectively. Such improved percentage of glycemic control among patients with T2DM was previously reported in a similar study from Japan [22]. Overall, the percentage of subjects achieving a target $\mathrm{HbA}_{1 \mathrm{c}}$ goal, in our study, was $73.6 \%$, whereas only $29 \%$ of the Japanese subjects achieved similar glycemic control results. At baseline, most of our patients, if not all, were on treatment and the proportion of glycemic control was over $40 \%$, as opposed to the $2.5 \%$ proportion reported in the Japanese study [21]. Interestingly, despite differences at baseline, the absolute improvement was similar $(\sim 30 \%)$ in 
Table 3a. Patient Satisfaction Questionnaire (PSQ-18) at Different Assessment Intervals

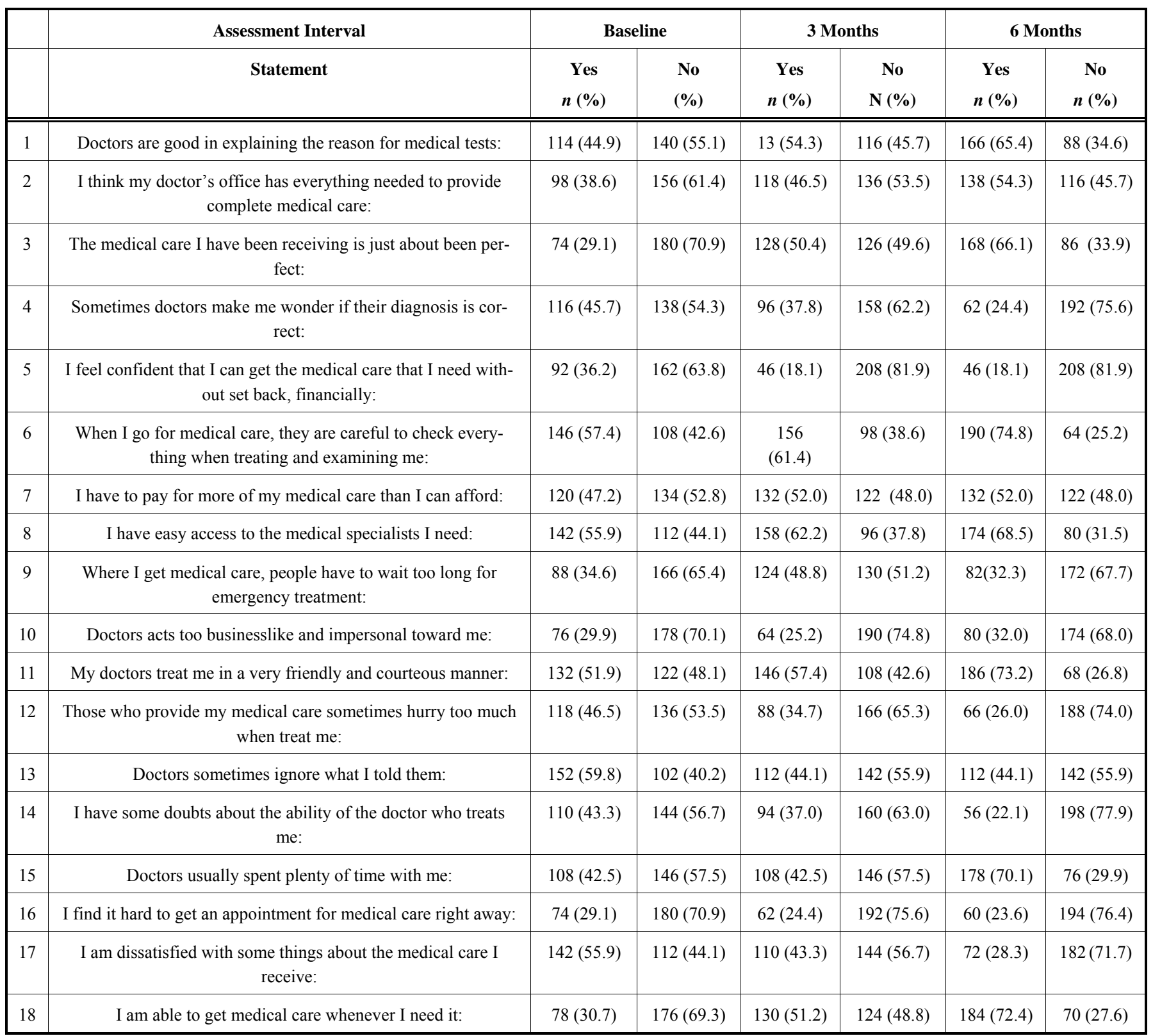

Table 3b. General Patient Satisfaction Questionnaire (PSQ-18) Scale Scores

\begin{tabular}{|c|c|c|c|c|c|}
\hline Subscale Parameter & Question Number (Average Scores) & Baseline & At 3 Months & At 6 Months & $p$ Value \\
\hline General satisfaction & 3 & $2.5 \pm 0.8$ & $3.4 \pm 0.9$ & $8 \pm 1.0$ & 0.02 \\
\hline \multirow[t]{3}{*}{ Technical quality } & 2 & $3.1 \pm 0.8$ & $3.7 \pm 1.0$ & $4.1 \pm 0.6$ & 0.01 \\
\hline & 4 & $2.7 \pm 0.7$ & $2.9 \pm 0.9$ & $3.4 \pm 0.8$ & $0.06^{*}$ \\
\hline & 14 & $2.6 \pm 0.9$ & $3.3 \pm 0.9$ & $3.9 \pm 0.9$ & 0.04 \\
\hline \multirow[t]{2}{*}{ Interpersonal manner } & 10 & $2.5 \pm 0.6$ & $3.6 \pm 0.9$ & $4.2 \pm 0.7$ & 0.01 \\
\hline & 11 & $2.6 \pm 0.7$ & $2.8 \pm 0.8$ & $3.7 \pm 0.6$ & 0.03 \\
\hline
\end{tabular}


Table 3b. Contd.....

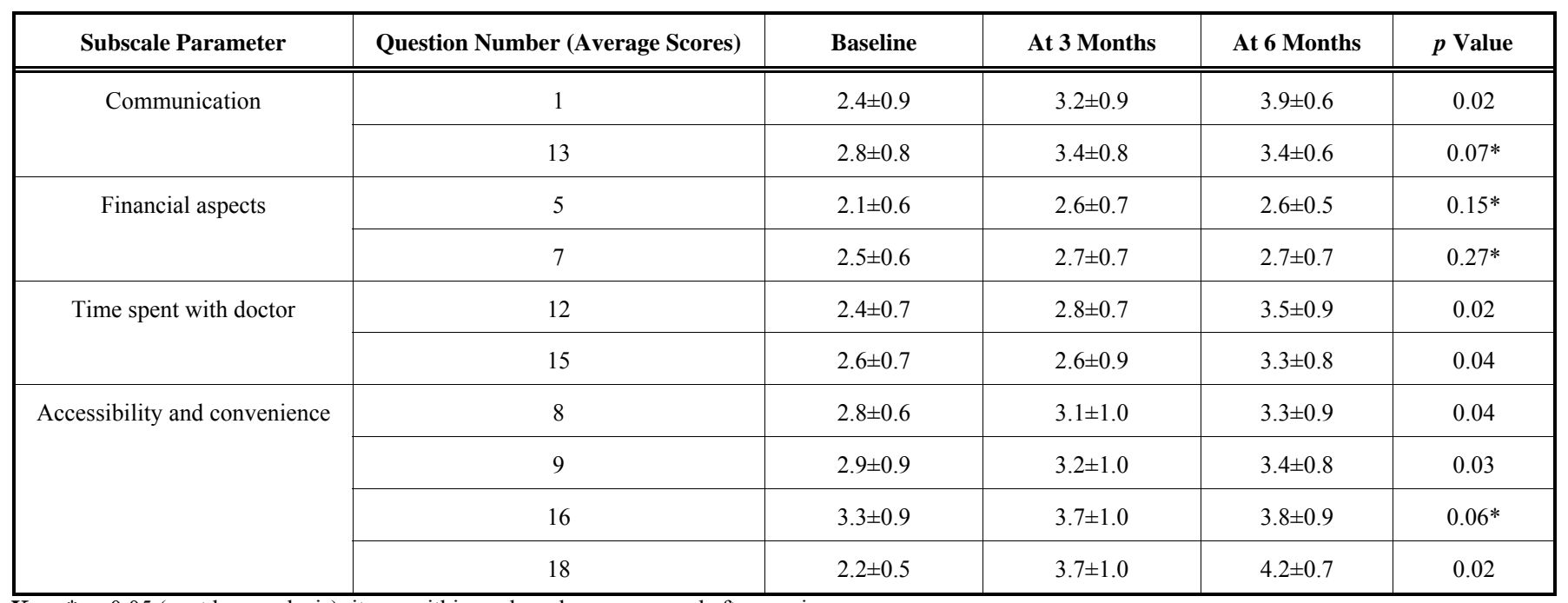

Key: ${ }^{*} p>0.05$ (post hoc analysis), items within each scale are averaged after scoring.

both studies. Moreover, the improved glycemic control was also evident from the significant reduction in FBG. The benefits of glycemic control are underscored by its association with reduced diabetes complications [11], and improved quality of life [12]. Tight glycemic control with $\mathrm{HbA}_{1 \mathrm{c}}$ levels $<7 \%$ has commonly been recommended to prevent macrovascular and microvascular complications [23]. Several studies have demonstrated that tight glycemic control reduces the risk for microvascular complications [24], but other major studies have challenged the notion that tight glycemic control reduces macrovascular complications $[25,26]$. This is particularly important as macrovascular disease is a primary cause of morbidity and mortality in T2DM [27]. We could not establish a causal relationship between glycemic control and diabetes complications in our study, presumably due to a limited follow up time. It should be noted that our approach to glycemic management was individualized taking into consideration the existence of comorbid conditions as recommended by others [28]. On one hand, our findings highlight a suboptimal T2DM management, at baseline, in the studied population. On the other, the significantly high percentage of patients with controlled hyperglycemia found in our study is of importance and may have possibly contributed to the low diabetes complication and increased patient satisfaction. Lower BP combined with an intensive glucose control has been shown to be independently beneficial to reduce morbidity in T2DM [29], thus. The significant reduction in BP shown in our study subjects is likely to be of added value.

Regarding patient satisfaction about the healthcare delivery and standards, our results showed a significantly improved satisfaction level in various aspects of general medical care. Patients answered positively to most domains and sub domains of PSQ-18, namely; general satisfaction, technical quality of the service, interpersonal manner, communication, time spent with the doctor, accessibility and convenience, but not included financial aspects. Perhaps, while patients may have changed their opinion about a particular domain, their financial status remained the same, especially that all subjects were covered by healthcare insurance companies. The difference in mean values between baseline, au- dit and re-audit phases were significant $(\mathrm{p}<0.05)$. Overall, the results on patient satisfaction have arisen as a critical outcome of medical care due to increasing eminence on patients as consumers of service [30]. Patient satisfaction has been connected with patient adherence to medical recommendations [31], preparedness to initiate malpractice legal action [32], doctor choice [33], and disenrollment from prepaid health plans [34]. Hence, recognizing the importance of patient satisfaction in assessing quality of medical care is inevitably a fundamental aspect of not only assessing the quality of care, but also assessing the clinical outcome of diabetes care.

Despite the suboptimal diabetes control at baseline, the improvements shown in our study regarding glycemic control, BP, lipid profile, and patient satisfaction, among patients with T2DM were encouraging. We clearly demonstrated an opportunity to improve the current situation, through the implementation of a more aggressive T2DM management and care in both primary healthcare, and tertiary facilities in the UAE, where the prevalence of DM is rampant $[4,5]$. Our approach of interventional audit of T2DM care has included intensified and supervised lifestyle modifications; nutritional therapy, physical activity, and selfmanagement strategies, and therapeutic interventions as appropriate.

The rational to implement care changes is underscored by 3 distinct components; available resources (health facilities), willingness (among policy makers), and above all, a compelling gap between the current practice and anticipated goals [35]. Our study demonstrated a clear gap in various components of T2DMmanagement, i.e., in glycemic control, BP, LDL-C, and patient satisfaction, hence providing a clear rational for action. Whether such approach can be expanded to the wider healthcare system is subject to more conclusive results and proven efficacy in the long term.

\section{CONCLUSION}

The results of the interventional audit were generally positive and emphasized the feasibility of improving the current clinical practice. Our individualized approach has 
helped us to achieve a better target in glycemic and BP control as well as patient satisfaction. Further research is needed to understand the long-term impact of our structured approach to improve the quality of T2DM care in the UAE.

\section{ACKNOWLEDGEMENTS}

We wish to express our gratitude for College of Medicine for their support. We acknowledge that this research was supported by a grant from UAE University.

\section{CONFLICT OF INTEREST}

The authors confirm that this article content has no conflicts of interest.

\section{REFERENCES}

[1] International Diabetes Federation IDF Diabetes Atlas, $5^{\text {th }}$ ed. International Diabetes Federation, 2011. Available: http://www.diabetesatlas.org/. [Accessed 2012 July 15].

[2] Zimmet P, Alberti KG, Shaw J. Global and societal implications of the diabetes epidemic. Nature 2001; 414: 782-7.

[3] Alberti KG, Zimmet P, Shaw J. International Diabetes Federation: a consensus on Type 2 diabetes prevention. Diabet Med 2007; 24: 451-63.

[4] Malik M, Bakir A, Abi Saab B, Roglic G, King H. Glucose intolerance and associated factors in the multiethnic population of the United Arab Emirates: results of a national survey. Diabetes Res Clin Pract 2005; 69: 188-95.

[5] Saadi H, Carruthers SG, Nagelkerke N, et al. Prevalence of diabetes mellitus and its complications in a population-based sample in Al Ain, United Arab Emirates. Diabetes Res Clin Pract 2007; 78: 369-77.

[6] Al-Maskari F, El-Sadig M, Nagelkerke N. Assessment of the direct medical costs of diabetes mellitus and its complications in the United Arab Emirates. BMC Public Health 2010; 10: 679.

[7] Bero LA, Grilli R, Grimshaw JM. Closing the gap between research and practice: an overview of systematic reviews of interventions to promote the implementation of research findings. BMJ 1998; 317: 465-8.

[8] Principles for best practice in clinical audit. National Institute for Clinical Excellence, Roy Coll of Nursing, University of Leicester, UK: Rodcliffe medical press 2002.

[9] Donabedian A. Explorations in quality assessment and monitoring. Ann Arbor, Michigan: Health Administration Press 1980; Vol.1.

[10] Victor M. Montori, Mercè F-B. Glycemic control in type 2 diabetes: time for an evidence-based about-face? Ann Intern Med 2009; 150: 803-8.

[11] Shim YT, Lee J, Toh MP, Tang WE, Ko Y. Health-related quality of life and glycaemic control in patients with Type 2 diabetes mellitus in Singapore. Diabet Med 2012; 29: e241-8.

[12] Mukherjee AK, Reddy VS, Shah S, et al. Quality of life as a key indicator of patient satisfaction and treatment compliance in people with type 2 diabetes mellitus in the IMPROVE study. J Indian Med Assoc 2009; 107: 464-70.

[13] Afandi B, Ahmed S, Saadi H, et al. Audit of a diabetes clinic at tawam hospital, united arab emirates, 2004-2005. Ann N Y Acad Sci 2006; 1084: 319-24.

[14] Reed RL, Revel AO, Carter A, Saadi HF, Dunn EV. A clinical trial of chronic care diabetic clinics in general practice in the United
Arab Emirates: a preliminary analysis. Arch Physiol Biochem 2001; 109: 272-80.

[15] Khattab MS, Swidan AM, Farghaly MN, et al. Quality improvement programme for diabetes care in family practice settings in Dubai. East Mediterr Health J 2007; 13: 492-504.

[16] Institute for clinical systems improvement-ICSI.Healthcare Guideline Management of Type 2 Diabetes Mellitus Eleventh Edition/November, 2006.

[17] Health Authority-Abu Dhabi (HAAD). HAAD Standards for diagnosis, management and data reporting for diabetes. Abu Dhabi: 2009. Available at www.haad.ae

[18] Ware JE, Snyder MK, Wright WR. Development and validation of scales to measure patient satisfaction with medical care services. Part A: Review of literature, overview of methods and results regarding construction of scales. (NTIS Publication No. PB 288329). Vol I. Springfield, VA: National Technical Information Service, 1976

[19] Marshall GN, Hays RD The Patient Satisfaction Questionnaire Short-Form (PSQ-18), (RAND, Santa Monica, CA). The RAND Corporation 1994; P. 7865.

[20] American Diabetes Association.Standards of medical care for patients with diabetes mellitus. Diabetes Care 2002; 25: S33-49.

[21] Bradley C. Diabetes treatment satisfaction questionnaire. In: Bradly C, Ed. Handbook of Psychology and Diabetes: A Guide to Psychological Measurement in Diabetes Research and Practice. Chur, Switzerland: Harwood Academic Publisher 1994; pp. 111-32.

[22] Hirohito S, Koichi K, Hirofumi T, Nobuhiro Y, Masashi K. Outcome of One-year of Specialist Care of Patients with Type 2 Diabetes: A Multi-Center Prospective Survey (JDDM 2). Intern Med 2006; 45: 589-7.

[23] Stettler C, Allemann S, Juni P, et al. Glycemic control and macrovascular disease in types 1 and 2 diabetes mellitus: metaanalysis of randomized trials. Am Heart J 2006; 152: 27-38.

[24] Lawrence B. Benefits and risks for intensive glycemic control in patients with diabetes mellitus. Am J Med Sci 2012; 343: 17-20.

[25] Gerstein HC, Miller ME, Byington RP, et al. Action to Control Cardiovascualr Risk in Diabetes Study Group: Effects of intensive glucose lowering in type 2 diabetes. N Engl J Med 2008; 358: 2545-9.

[26] Patel A, MacMahon S, Chalmers J, et al. ADVANCE collaborative group: Intensive blood glucose control and vascular outcomes in patients with type 2 diabetes. N Engl J Med 2008; 358: 2560-72.

[27] Laing SP, Swerdlow AJ, Slater SD, et al. Mortality from heart disease in a cohort of 23,000 patients with insulin-treated diabetes. Diabetologia 2003; 46: 760-5.

[28] Ismail-Beigi F.Pathogenesis and glycemic management of type 2 diabetes mellitus: a physiological approach. Arch Iran Med 2012; 15: 239-46.

[29] Chalmers J, Arima H. Importance of blood pressure lowering in type 2 diabetes: focus on ADVANCE. J Cardiovasc Pharmacol 2010; 55: 340-7.

[30] Davies AR, Ware J. Involving consumers in quality of care assessment. Health Affairs 1988; 7: 33-48.

[31] Sherbourne CD, Hays RD, Ordway L, DiMatteo MR, Kravitz R Antecedents of adherence to medical recommendations: results from the Medical Outcomes Study. J Behav Med 1992; 15: 447-68.

[32] Vaccarino JM. Malpractice: The problem in perspective. JAMA 1977; 238: 861-3.

[33] Marquis MS, Davies AR, Ware JE. Patient satisfaction and change in medical care provider: A longitudinal study. Med Care 1983; 21: $821-9$.

[34] Ware JE, Davies AR. Behavioural consequences of consumer dissatisfaction with medical care. Eval Prog Plann 1983; 6: 291-7.

[35] Tom AE. Diabetes Quality Improvement: Rigor and Ridicule. Clin Diabetes 2009; 27: 49-51. 